\title{
Health Care Delivery Practices in Huntington's Disease Specialty Clinics: An International Survey
}

Jan C. Frich ${ }^{\mathrm{a}, \mathrm{b}, *}$, Daniela Rae ${ }^{\mathrm{c}, \mathrm{d}}$, Richard Roxburgh ${ }^{\mathrm{e}}$, Zofia H. Miedzybrodzkac ${ }^{\mathrm{c}}$, Mary Edmondson ${ }^{\mathrm{f}}$, Erika Bjorklund Pope ${ }^{\mathrm{g}}$, LaVonne Goodman ${ }^{\mathrm{h}}$, Monica S. Haddad ${ }^{\mathrm{i}}$, Joe Giuliano ${ }^{\mathrm{j}}$, Eugene C. Nelson ${ }^{\mathrm{k}}$, Mark Guttman ${ }^{1}$ and Martha Nance ${ }^{\mathrm{m}, \mathrm{n}}$

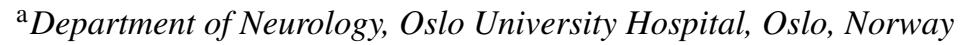

${ }^{\mathrm{b}}$ Institute of Health and Society, University of Oslo, Oslo, Norway

${ }^{\mathrm{c}}$ Department of Clinical Genetics, NHS Grampian, Aberdeen, Scotland, UK

${ }^{\mathrm{d}}$ Health Services Research Unit, University of Aberdeen, Aberdeen, Scotland, UK

${ }^{\mathrm{e}}$ Department of Neurology, Auckland City Hospital, Auckland, New Zealand

${ }^{\mathrm{f}}$ HD Reach, Raleigh, NC, USA

${ }^{\mathrm{g}}$ Pacific Northwest University of Health Sciences, Yakima, WA, USA

${ }^{\mathrm{h}}$ Huntington's Disease Drug Works, Lake Forest Park, WA, USA

${ }^{\mathrm{i}}$ Department of Neurology, School of Medicine, University of São Paulo, São Paulo, SP, Brazil

${ }^{\mathrm{j} C H D I}$ Management/CHDI Foundation, Princeton, NJ, USA

${ }^{\mathrm{k}}$ The Dartmouth Institute for Health Policy and Clinical Practice, Geisel School of Medicine, Dartmouth College, NH, USA

${ }^{1}$ Centre for Movement Disorders, Toronto, ON, Canada

m Struthers Parkinson's Center, Golden Valley, MN, USA

${ }^{\mathrm{n}}$ Hennepin County Medical Center, MN, USA

\begin{abstract}
.
Background: Little is known about the organization of clinical services for Huntington's disease (HD).

Objective: To describe how health care services are organized and delivered in HD-clinics taking part in or eligible for the Enroll-HD study.

Methods: In 2014, a 69-item survey was administered to sites taking part in or eligible for the Enroll-HD study.

Results: Of 231 sites surveyed, 121 (52.2\%) sites in Europe, North America, Latin America, and Oceania responded. Most sites in the sample serve large populations, with $61.1 \%$ serving more than 1.5 million people, and a further $33 \%$ serving $>500,000$. Almost all (86.0\%) centers see patients from outside their region. The majority of centers (59.7\%) follow 50-199 patients, $21.9 \%$ care for more than 200. Most centers provide care in all stages of HD, and nearly all review pre-symptomatic cases. Multidisciplinary case reviews are offered in $54.5 \%$ of sites, with outreach clinics offered by $48.1 \%$. Videoconferencing and telemedicine are used by $23.6 \%$. Separate consultations for caregivers are offered in more than half of the centers. Most centers (70.4\%) report following published guidelines or local care pathways for HD.
\end{abstract}

${ }^{*}$ Correspondence to: Jan C. Frich, Institute of Health and Society, University of Oslo, PO Box 1089 Blindern, N-0318 Oslo,
Norway. Tel.: +47 228505 24; Fax: +47 22845091; E-mail: jan.frich@medisin.uio.no. 
Conclusions: Most centers serve a large population and use a multidisciplinary approach. The survey gives insight into factors underpinning HD service delivery globally. There is a need for more in-depth studies of clinical practice to understand how services are organized and how such features may be associated with quality of care.

Keywords: Huntington's disease, health services, quality of health care

\section{INTRODUCTION}

Huntington's disease (HD) is a neurodegenerative genetic disorder with autosomal dominant inheritance [1], characterized by progressive motor abnormalities, cognitive impairment and psychiatric disturbances [1-3]. Clinical features of HD usually develop during adult life, most commonly between the ages of 30 to 60 years, and disease duration from first clinical symptoms through complete care dependency to death is approximately 15-20 years [1].

HD patients in early to middle stages of the disease may benefit from coordinated multidisciplinary health care services, including regular follow up, neurological and cognitive assessments, physiotherapy $[4,5]$, speech therapy training $[6,7]$, and occupational therapy [8]. Patients in advanced stages of the disease are usually dependent on fulltime personal care [9]. Family members and caregivers need support and guidance $[10,11]$. Young people who are at-risk are burdened with difficult family dynamics, uncertainty around gene status and in many cases parental caregiving.

At present, there is no curative treatment for HD, so treatment is aimed at alleviating symptoms, and maintaining and improving function and quality of life [1]. There is a high reliance on informal care in HD [12], and a study from Norway found that patients and caregivers report significant unmet needs for health services [13]. There is general agreement that comprehensive and multidisciplinary care is needed for individuals and families affected by HD [1, 14-17]. Coordination of services, including medical and clinical services and social and community resources, is central in multidisciplinary approach. Standards of care and guidelines for management of individuals and families affected by HD have been published with the purpose of being a foundation for further research and evaluation of care provided [17].

Multidisciplinary care is considered the gold standard in care delivery in complex chronic disease, including Huntington's disease [1]. Refinements in the organization of care delivery have improved quality of life and survival for patients with chronic disease, as demonstrated in cystic fibrosis $[18,19]$ and Parkinson's disease [20, 21]. Studies of outcomes related to multidisciplinary or integrated care in Parkinson's disease revealed mixed results [20, 21], suggesting that some components of multidisciplinary care may be more important than others. Another study revealed that hospitalization rates for patient with Parkinson's disease are lower in patients seen by neurologists compared to generalists [22].

The introduction of a HD nurse specialist resulted in decreased hospital admissions by $51 \%$, and hospitalization was more appropriate in those who were admitted, suggesting that care management services may be a critical component of service delivery in HD [23]. Overall, there is a lack of research into how care delivery influences outcomes in HD. Little is known about the variability in the organization of HD services globally, the sizes of populations served, and organization of HD-clinics.

Enroll-HD [NCT01574053] is an international, observational study and research platform that intends to follow a large cohort of individuals diagnosed with and at-risk for HD along with family controls and relatives who have tested gene-negative with detailed annual assessments and specimen collection. The study currently includes more than 130 study sites in North America, Europe, Latin America and Oceania, and has enrolled over 10,000 participants as of April 2016. In addtion, study sites in the European Huntington Disease Network's REGISTRY study [NCT01590589] are eligible for the Enroll-HD study. In order to explore structures and processes underpinning clinical management that may be relevant for improving the health and wellbeing for those affected by HD, the Care Improvement Committee (CIC), part of the Enroll-HD governance, performed a survey to describe how services are organized and delivered across HD-clinics taking part in or eligible for the Enroll-HD study.

\section{MATERIALS AND METHODS}

The Enroll-HD Care Improvement Committee developed a 69-item survey instrument that captures information on the populations served by HD-centers, characteristics of health care delivery and organiza- 
tion of centers. The survey instrument was developed through an iterative process by the members of the Care Improvement Committee, which consist of experienced HD-clinicians, patients' representatives and researchers, and seven study sites were involved in pilot testing of the instrument. In addition to questions with predefined categories, there was room for free-text comments. Quantitative data were analyzed using descriptive statistics, and free-text comments were read to assist data interpretation. The survey was distributed electronically in English using Survey Monkey ${ }^{\mathrm{TM}}$. A total of 231 principal investigators in Enroll-HD and other Enroll-HD eligible sites were invited by e-mail to respond to the survey between June 2014 and November 2014. Several reminders were sent to increase the response rate.

\section{RESULTS}

\section{Response rates}

Of 231 sites surveyed, 121 (52.2\%) responded. The response rates varied for individual items in the survey and across countries (Table 1). The response rate was $100 \%$ for Canada, New Zealand, Denmark and Norway, $83.3 \%$ for Brazil, $80.0 \%$ for Portugal, $78.6 \%$ for Italy, $76.5 \%$ for Germany, $60.0 \%$ for Poland, $52.0 \%$ for the United States of America, $53.8 \%$ for the United Kingdom, and $50.0 \%$ for France and the Netherlands. Response rates were less than 50\% for Argentina, Australia, Austria, Belgium, Chile, Colombo, Czech Republic, Finland, Ireland, Mexico, Peru, Russia and Spain.

\section{Population served by HD Clinics}

There was variability in size of population served by each HD center in our sample. The majority $(61.1 \%)$ of centers serves a population of more than 1.5 million people, with a further $27.3 \%$ serving $500,000-1.5$ million (Table 1 ). Only $11.5 \%$ of centers served a population of less than 500.000. One-third $(29.3 \%)$ ran clinics in more than one geographical location. Around half of patients (53.9\%) across all centers had less than 60 minutes estimated travelling time to the center.

\section{Frequency of clinical review offered}

The number of individuals followed up by a clinic on a regular basis varied across centers (Table 2). One-fifth (18.5\%) of centers cared for 1-49 patients,
Table 1

Characteristics of the population served

\begin{tabular}{lc}
\hline Survey item (number of respondents to the item) & $\mathrm{N}(\%)$ \\
\hline Size of population served $(\mathrm{N}=121)$ & \\
$\quad \leq 500.000$ & $14(11.5)$ \\
$500.001-1.500 .000$ & $33(27.3)$ \\
$1.500 .001-3.000 .000$ & $23(19.0)$ \\
$>3.000 .000$ & $51(42.2)$ \\
Clinic in more than one location $(\mathrm{N}=121)$ & \\
Yes & $36(29.7)$ \\
No & $85(70.3)$ \\
Groups of patients seen $(\mathrm{N}=117)$ & $110(94.0)^{*}$ \\
People at risk & $109(93.2)^{*}$ \\
Pre-symptomatic gene carriers & $116(99.2)^{*}$ \\
Symptomatic (early and mid-stage) & $108(92.3)^{*}$ \\
Symptomatic (late stages) & \\
Number of patients followed $(\mathrm{N}=119)$ & $22(18.5)$ \\
$1-49$ & $35(29.4)$ \\
$50-99$ & $36(30.3)$ \\
$100-199$ & $26(21.8)$ \\
$>200$ & $104(86.0)$ \\
See patients outside their region $(\mathrm{N}=121)$ & $17(14.0)$ \\
Yes & \\
No & $65(63.7)^{*}$ \\
Reasons for out of region referrals $(\mathrm{N}=102)$ & $72(70.6)^{*}$ \\
The nearest specialist center & $25(24.5)^{*}$ \\
Patient choice & $5(4.9)$ \\
Other reasons & $50(49.0)$ \\
Estimated travel time for patients $(\mathrm{N}=102)$ & $37(36.3)$ \\
$<30$ min & $10(9.8)$ \\
30-60 min & \\
$61-120$ min & \\
$>121$ min & \\
\hline
\end{tabular}

${ }^{*}$ Several response alternatives allowed to the survey item.

$29.4 \%$ followed 50-99, 30.3\% followed 100-199, and $21.8 \%$ cared for more than 200 patients. Onethird of centers $(33.6 \%)$ offered specialist inpatients beds for HD. The majority $(86.0 \%)$ reported seeing patients from outside their own geographical region, and reasons listed for such referrals were patient's own choice $(70.6 \%)$ and being the nearest specialist center $(63.7 \%)$. Among other reasons $(24.5 \%)$ listed were the center's reputation, being a research center and participating in clinical trials, and lack of expertise elsewhere.

\section{Mission statements}

One-quarter $(27.8 \%)$ of centers have a mission statement. Some centers are located within larger units with a mission statement, for example: "Our mission is to improve the quality of life of persons with movement disorders throughout the spectrum of their condition by offering patient and family centered services through an innovative multidisciplinary approach". Some statements were brief and general: "To provide the right care, at the right time, 
Table 2

Characteristics of service delivery in HD-centers

\begin{tabular}{|c|c|}
\hline Survey item (number of respondents to the item) & $\mathrm{N}(\%)$ \\
\hline \multicolumn{2}{|l|}{ Consultation in a clinic for } \\
\hline \multicolumn{2}{|l|}{ HD patients only $(\mathrm{N}=117)$} \\
\hline Yes & $50(42.7)$ \\
\hline No & $67(57.3)$ \\
\hline \multicolumn{2}{|l|}{ Access to specialist HD inpatient beds $(\mathrm{N}=110)$} \\
\hline Yes & $37(33.6)$ \\
\hline No & $73(66.4)$ \\
\hline \multicolumn{2}{|l|}{ Where are patients seen? $(\mathrm{N}=108)$} \\
\hline Outpatient clinic & $106(98.2)^{*}$ \\
\hline Inpatient ward & $32(29.6)^{*}$ \\
\hline Other & $8(7.4)^{*}$ \\
\hline \multicolumn{2}{|l|}{ Outreach visits in the community $(\mathrm{N}=108)$} \\
\hline Yes & $52(48.1)$ \\
\hline No & $56(51.9)$ \\
\hline \multicolumn{2}{|l|}{ Where outreach visits takes place $(\mathrm{N}=50)$} \\
\hline General practice/health center & $14(28.0)^{*}$ \\
\hline Specialist practice & $9(18.0)^{*}$ \\
\hline Patients' homes & $36(72.0)^{*}$ \\
\hline \multicolumn{2}{|c|}{ See patients in other hospitals/care facilities $(\mathrm{N}=106)$} \\
\hline Yes & $51(48.1)$ \\
\hline No & $55(51.9)$ \\
\hline \multicolumn{2}{|l|}{ Use of videoconferencing/telemedicine $(\mathrm{N}=106)$} \\
\hline Yes & $25(23.6)$ \\
\hline No & $81(76.4)$ \\
\hline \multicolumn{2}{|l|}{$\begin{array}{l}\text { With whom do you use videoconferencing } \\
\text { or telemedicine? }(\mathrm{N}=24)\end{array}$} \\
\hline Patient consultations & $11(45.8)^{*}$ \\
\hline Other clinicians & $15(62.5)^{*}$ \\
\hline Other & $6(25.0)^{*}$ \\
\hline \multicolumn{2}{|l|}{$\begin{array}{l}\text { Multidisciplinary case review meetings } \\
\text { for professionals }(\mathrm{N}=110)\end{array}$} \\
\hline Yes & $60(54.5)$ \\
\hline No & $50(45.5)$ \\
\hline
\end{tabular}

*Several response alternatives allowed to the survey item.

in the right place", and "To provide the best clinical care to HD patients". Others focus on being a multidisciplinary clinic: " ... to provide the best clinical care and services for individuals affected with HD and their families. This includes clinical and social services, educational outreach and research opportunities". One group of centers referred to the HDSA Center of Excellence guidelines, and had built their mission statement according to these, for example: "The HDSA Center of Excellence at [hospital] is dedicated to serving the needs of those affected by Huntington's disease (HD). Our goals are (1) to maximize quality of life, (2) to provide education and training opportunities about HD and (3) to conduct research into the causes and consequences for HD and into potential treatments".

\section{Organization of care delivery}

Most centers (86.8\%) offer consultations to those at-risk and to presymptomatic gene carriers as well as those with a clinical diagnosis of HD (Table 1). Free text comments suggest that many centers are embedded within larger clinics, such as a Department of Neurology or Department of Medical Genetics, and that it is commonplace to run HD-clinics on certain days during the week. Almost half (48.1\%) of the centers offer outreach visits in the community, and $72 \%$ of centers will sometimes see patients in their own homes (Table 2). Half of the clinics $(48.1 \%)$ report offering outreach services such as seeing patients in other hospitals and care facilities, such as nursing homes, residential care facilities, and psychiatric hospitals. Interestingly, videoconferences and telemedicine was used by almost a quarter $(23.6 \%)$ of clinics. Multidisciplinary case reviews were arranged by a majority $(54.5 \%)$ of centers.

\section{Healthcare specialties, staff and services in centers}

Twenty-two different health professional specialties were represented at HD clinics (Table 3); in addition to the specialties listed in the survey, a number of centers listed additional specialists in free-text comments, such as gastroenterologist, legal advisor, dementia coordinator, and palliative care. The specialists most frequently included in HD clinics were neurologists $(66.7 \%)$, neuropsychologists $(57.3 \%)$, research nurses $(52.1 \%)$, geneticists (49.6\%), genetic counsellor (48.7\%), psychiatrist (45.3\%), social worker (43.6\%), and specialist nurse (41.9\%). Centers offered a wide variety of services such as clinical review, assessment and review of medication, neurological examination, neuropsychological assessment, diagnostic and predictive testing, genetic counseling and behavioral and crisis management (Table 4).

\section{Clinical routines and management}

Frequency of follow-up varied according to disease stage (Table 5). Most patients at risk are seen annually (43\%) or as requested by the patient (40\%). Early stage patients are usually seen either every sixth months $(40 \%)$ or annually (39\%). Mid stage patients are seen more often with $28 \%$ being seen three monthly, and $47 \%$ being seen six monthly. Late stage patients are seen a little less frequently than mid stage patients.

About half $(53.7 \%)$ of the clinics offer new patients between $46 \mathrm{~min}$ and 1 hour consultations; with a further fifth $(19.5 \%)$ offering longer appointments 
Table 3

Characteristics of the health care staff in HD-centers $(\mathrm{N}=117)$

\begin{tabular}{lc}
\hline Professionals and staff working for the center & $\mathrm{N}(\%)$ \\
\hline Neurologist & $78(66.7)$ \\
Neuropsychologist & $67(57.3)$ \\
Research nurse & $61(52.1)$ \\
Geneticist & $58(49.6)$ \\
Genetic counselor & $57(48.7)$ \\
Research assistant & $57(48.7)$ \\
Psychiatrist & $53(45.3)$ \\
Social worker & $51(43.6)$ \\
Specialist nurse & $49(41.9)$ \\
Secretarial or support staff & $47(40.2)$ \\
Speech and language therapist & $42(35.9)$ \\
Physiotherapist & $36(30.8)$ \\
Psychologist & $32(27.4)$ \\
Dietitian & $32(27.4)$ \\
Occupational therapist & $30(25.6)$ \\
Family group representative/ & $25(21.4)$ \\
$\quad$ Huntington's disease association advisor & \\
Neuropsychiatrist & $22(18.8)$ \\
Nurse practitioner & $22(18.8)$ \\
Care coordinator & $17(14.5)$ \\
General practitioner, dentist, youth worker, other & $25(21.4)$ \\
\hline
\end{tabular}

Table 4

Content of service provision in HD-centers $(\mathrm{N}=111)$

\begin{tabular}{lr}
\hline Service provided & $\mathrm{N}(\%)$ \\
\hline $\begin{array}{l}\text { Clinical review, assessment and review } \\
\text { of medication }\end{array}$ & $107(96.4)$ \\
Neurological examination & $107(96.4)$ \\
Neuropsychological assessment & $95(85.6)$ \\
Diagnostic testing & $95(85.6)$ \\
Genetic counseling & $89(80.2)$ \\
Behavioral management & $85(76.6)$ \\
Predictive testing & $84(75.7)$ \\
Crisis management & $81(73.0)$ \\
Psychological support & $75(67.6)$ \\
Therapeutic counseling & $72(64.9)$ \\
Speech and language therapy & $54(48.7)$ \\
Physiotherapy & $51(46.0)$ \\
Benefit advice & $50(45.1)$ \\
Educational services/training & $46(41.4)$ \\
Occupational therapy & $43(38.7)$ \\
Peer support groups & $34(30.6)$ \\
Housing support & $29(26.1)$ \\
Respite care & $16(14.4)$ \\
Other (dental advice, therapy, nutrition advice, & $15(13.5)$ \\
$\quad$ support groups and advanced neuroimaging) & \\
\hline
\end{tabular}

(Table 6). Time spent with the lead clinician for return patients was reported never to be more than $60 \mathrm{~min}$ utes, and most consultations (70.7\%) lasted between 16 and 45 minutes. Almost all clinics (94.1\%) offer appointments to caregivers. Clinics offer caregivers to be seen together with the patient $(94.8 \%)$, and a majority of clinics also offer separate consultations for caregivers (58.3\%). In addition to scheduled vis- its, more than half $(55.0 \%)$ of the centers offered face to face interaction with patients between clinic visits (Table 5). Additional support was provided by nearly all clinics by telephone (98.2\%), and sometimes by email $(68.5 \%)$ or through videoconferencing $(10.8 \%)$. About half of the centers $(57.3 \%)$ formulated individualized care management plans. Most centers (70.4\%) reported following published guidelines or local pathways for HD.

\section{DISCUSSION}

This survey provides some insight into factors underpinning HD service delivery around the world. Our results suggest that the majority of centers serve large populations. Half of the centers offer community based care or domiciliary visits, and one-quarter use videoconferencing and telemedicine. We also found that most centers provide care in all stages of $\mathrm{HD}$, including to asymptomatic and at-risk individuals, and that there seems to be consistent patterns of the frequency of follow-up according to disease stage.

\section{Multidisciplinary care}

The literature strongly promotes a multidisciplinary approach to HD [1, 14-17], and our study suggests that the majority of HD centers surveyed provides multidisciplinary care. More than half of the clinics are staffed with a neurologist, neuropsychologist, research nurse and/or a geneticist, but the presence of other professional groups varies. Notably, less than half the centers include a physiotherapist, occupational, speech and language, or nutritional therapist (dietitian). It may be that other services have good access to these specialties and services in the health care system. This variability in access to services at different centers suggests that more research should be conducted to understand how centers are organized and how they interact with the rest of the local health care system.

\section{Research on health outcomes in HD}

While there is research in support of multidisciplinary approaches to other chronic diseases, little is known about how health care delivery models impact on outcomes for patients and family members confronting this genetic disorder of mid-adulthood. We think our results will help in the design of future studies of how care provision may be associated 
Table 5

Follow-up regimen in HD-centers for different categories of patients

\begin{tabular}{|c|c|c|c|c|c|c|}
\hline & None & 3 months & 6 months & Annual & Bi-annual & Patient's request \\
\hline Patient category & $\%$ & $\%$ & $\%$ & $\%$ & $\%$ & $\%$ \\
\hline At risk/presymptomatic $(\mathrm{N}=97)$ & 4 & 3 & 9 & 43 & 1 & 40 \\
\hline Early stage $(\mathrm{N}=100)$ & 1 & 13 & 40 & 39 & 1 & 6 \\
\hline Mid stage $(\mathrm{N}=100)$ & 0 & 28 & 47 & 19 & 0 & 6 \\
\hline Late stage $(\mathrm{N}=94)$ & 1 & 28 & 35 & 22 & 1 & 13 \\
\hline
\end{tabular}

Table 6

Characteristics of patients' consultations and caregivers' follow-up

\begin{tabular}{|c|c|}
\hline Survey item (number of respondents to the item) & $\mathrm{N}(\%)$ \\
\hline \multicolumn{2}{|l|}{$\begin{array}{l}\text { Time spent with the lead clinician } \\
\text { for new patients }(N=41)\end{array}$} \\
\hline $0-15 \mathrm{~min}$ & $0(0)$ \\
\hline $16-30 \mathrm{~min}$ & $5(12.2)$ \\
\hline $31-45 \mathrm{~min}$ & $6(14.6)$ \\
\hline $46-60 \min$ & $22(53.7)$ \\
\hline$>60 \min$ & $8(19.5)$ \\
\hline \multicolumn{2}{|l|}{$\begin{array}{l}\text { Time spent with lead clinician } \\
\text { for returning patients }(\mathrm{N}=41)\end{array}$} \\
\hline $0-15 \mathrm{~min}$ & $4(9.8)$ \\
\hline $16-30 \mathrm{~min}$ & $15(36.6)$ \\
\hline $31-45 \mathrm{~min}$ & $14(34.2)$ \\
\hline $46-60 \mathrm{~min}$ & $8(19.5)$ \\
\hline \multicolumn{2}{|l|}{ Caregivers seen in the clinic $(\mathrm{N}=102)$} \\
\hline Yes & $96(94.1)$ \\
\hline No & $6(5.9)$ \\
\hline \multicolumn{2}{|l|}{ Consultation services for caregivers $(\mathrm{N}=96)$} \\
\hline Together with patient & $91(94.8)$ \\
\hline Separately at the same clinic & $56(58.3)$ \\
\hline Separately at different location & $9(9.4)$ \\
\hline Other & $9(9.4)$ \\
\hline \multicolumn{2}{|l|}{ Face to face interactions between visits $(\mathrm{N}=111)$} \\
\hline Yes & $61(55.0)$ \\
\hline No & $50(45.0)$ \\
\hline \multicolumn{2}{|l|}{ If yes, where? $(\mathrm{N}=61)$} \\
\hline Outpatient clinic & $50(82.0)$ \\
\hline Nursing homes & $29(47.5)$ \\
\hline Inpatient ward/psychiatric hospital & $25(41)$ \\
\hline Patients' homes & $24(39.3)$ \\
\hline Residential care facility & $20(32.8)$ \\
\hline \multicolumn{2}{|l|}{ Non-face to face support $(\mathrm{N}=111)$} \\
\hline Telephone & $109(98.2)$ \\
\hline Email & $75(68.5)$ \\
\hline Videoconferencing & $12(10.8)$ \\
\hline \multicolumn{2}{|l|}{$\begin{array}{l}\text { Formulate individualized care } \\
\text { management plans }(\mathrm{N}=110)\end{array}$} \\
\hline Yes & $63(57.3)$ \\
\hline No & $47(42.7)$ \\
\hline \multicolumn{2}{|l|}{ Follow guideline or local care pathway $(\mathrm{N}=108)$} \\
\hline Yes & $76(70.4)$ \\
\hline No & $32(29.6)$ \\
\hline
\end{tabular}

with favourable patient and family outcomes. The variation in service delivery offers the opportunity for the parent Enroll-HD study to elucidate whether having such specialties integrated into the clinic is associated with better outcomes in HD. Documentation of effects and outcomes has become important as patients, families, clinicians advocate improving funding of care and support systems. While this study begins to approach this problem from the clinical service perspective, there is a need understand more about how structural and processual factors are associated with good quality outcome measures. The ultimate goal should be to develop models of care that improve outcomes in HD.

\section{Strengths and weaknesses of the study}

The overall response rate in this study was $52.2 \%$, with variation in response rates across countries. Non-responders could have introduced selection bias. There may be regional differences in the degree to which HD-care is centralized, and patients may receive care outside of specialty HD clinics, or may also lack access to professional care. As the centers surveyed are those that are participating in or eligible for Enroll-HD, centers not involved in research and small centers are not represented in our sample. Centers in our sample may be able to offer a higher level of services compared with other centers, partly as a result of funding from research. Still, the study's strength is that it presents data from a large number and range of HD-centers that are involved in research worldwide, and it is the first study to map health care delivery practices in HD globally. With these limitations in mind one may question to what extent our findings are generalizable to HD-care in general. Still we think our findings give valuable insights into variations and patterns of HD care delivery.

\section{CONCLUSION}

Most centers in this study serve a large population and use a multidisciplinary approach. The survey gives insight into factors underpinning HD service delivery globally. There is a need for more in-depth studies of clinical practice to understand how services are organized and how such features may be associated with quality of care. 


\section{ACKNOWLEDGMENTS}

The CHDI Foundation, Inc. funds Enroll-HD and the activities of the Enroll-HD Care Improvement Committee, including the present survey. We would like to acknowledge the Enroll-HD and REGISTRY administrative staff that assisted in the recruitment of sites and sites that completed the survey.

\section{CONFLICT OF INTEREST}

The authors have no conflict of interest to report.

\section{REFERENCES}

[1] Bates PG, Tabrizi SJ, Jones L. Huntington's disease. 4th Edition. Oxford: Oxford University Press, 2014.

[2] Papoutsi M, Labuschagne I, Tabrizi SJ, Stout JC. The cognitive burden in Huntington's disease: Pathology, phenotype, and mechanisms of compensation. Mov Disord. 2014;29(5):673-83. doi: 10.1002/mds.25864

[3] Paulsen JS. Cognitive impairment in Huntington's disease: Diagnosis and treatment. Curr Neurol Neurosci Rep. 2011;11(5):474-83. doi: 10.1007/s11910-011-0215-x

[4] Busse M, Quinn L, Debono K, Jones K, Collett J, Playle $\mathrm{R}$, et al. A randomized feasibility study of a 12-week community-based exercise program for people with Huntington's disease. J Neurol Phys Ther. 2013;37(4):149-58. doi: 10.1097/NPT.0000000000000016

[5] Piira A, van Walsem MR, Mikalsen G, Nilsen KH, Knutsen S, Frich JC. Effects of a one year intensive multidisciplinary rehabilitation program for patients with Huntington's disease: A prospective intervention study. PLoS Curr. 2013;5.pii: ecurrents.hd.9504af71e0d1f 87830c25c394be47027. doi: 10.1371/currents.hd.9504af 71e0d1f87830c25c394be47027

[6] Hamilton A, Heemskerk A-W, Loucas M, TwistonDavies R, Matheson KY, Simpson SA, et al. Oral feeding in Huntington's disease: A guideline document for speech and language therapists. Neurodegen Dis Manage. 2012;2(1);45-53. doi:10.2217/nmt.11.77

[7] Hamilton A, Ferm U, Heemskerk A-W, Twiston-Davies R, Matheson KY, Simpson SA, et al. Management of speech, language and communication difficulties in Huntington's disease. Neurodegen Dis Manage. 2012;2(1): 67-77. doi:10.2217/nmt.11.78

[8] Cook C, Page K, Wagstaff A, Simpson SA, Rae D. Development of guidelines for occupational therapy in Huntington's disease. Neurodegen Dis Manage. 2012;2(1):79-87. doi:10.2217/nmt.11.81

[9] Simpson SA. Late stage care in Huntington's disease. Brain Res Bull. 2007;72(2-3):179-81.

[10] Røthing M, Malterud K, Frich JC. Caregiver roles in families affected by Huntington's disease: a qualitative interview study. Scand J Caring Sci. 2014;28(4):700-5. doi: $10.1111 /$ scs. 12098
[11] Forrest Keenan K, Miedzybrodzka Z, van Teijlingen E, McKee L, Simpson SA. Young people's experiences of growing up in a family affected by Huntington's disease. Clin Genet. 2007;71(2):120-9.

[12] Busse M, Al-Madfai H, Kenkre J, Landwehrmeyer GB, Bentivoglio AR, Rosser A et al. Utilisation of healthcare and associated services in Huntington's disease: a data mining study. PLoS Curr. 2011;3:RRN1206. doi: 10.1371/currents.RRN1206

[13] van Walsem MR, Howe EI, Iversen K, Frich JC, Andelic N. Unmet needs for health care and social support services in patients with Huntington's disease: A cross-sectional population-based study. Orphanet J Rare Dis. 2015;10:124. doi: 10.1186/s13023-015-0324-8

[14] Nance MA. Comprehensive care in Huntington's disease: a physician's perspective. Brain Res Bull. 2007;72(2-3):1758.

[15] Nance M, Paulsen JS, Rosenblatt A, Wheelock V. A Physician's guide to the management of Huntington's disease, 3. Ed. New York, NY: Huntington's Disease Society of America, 2011. Available from: http://hdsa.org/wpcontent/uploads/2015/03/PhysiciansGuide_3rd-Edition.pdf

[16] Veenhuizen RB, Tibben A. Coordinated multidisciplinary care for Huntington's Disease. An outpatient department. Brain Res Bull. 2009;80(4-5):192-5. doi: 10.1016/j.brainresbull.2009.06.017

[17] Simpson SA, Rae D. A standard of care for Huntington's disease: who, what and why. Neurodegen Dis Manage. 2012;2(1):1-5. doi:10.2217/nmt.11.85

[18] Mogayzel PJ, Dunitz J, Marrow LC, Hazle LA. Improving chronic care delivery and outcomes: the impact of the cystic fibrosis Care Center Network. BMJ Qual Saf. 2014;23(Suppl 1):i3-i8. doi: 10.1136/bmjqs-2013-002363

[19] Marshall BC, Nelson EC. Accelerating implementation of biomedical research advances: Critical elements of a successful 10 year Cystic Fibrosis Foundation healthcare delivery improvement initiative. BMJ Qual Saf. 2014;23(Suppl 1):i95-i103. doi: 10.1136/bmjqs-2013002790

[20] van der Marck MA, Bloem BR, Borm GF, Overeem S, Munneke M, Guttman M. Effectiveness of multidisciplinary care for Parkinson's disease: A randomized, controlled trial. Mov Disord. 2013;28(5):605-11. doi: 10.1002/mds.25194

[21] van der Marck MA1, Munneke M, Mulleners W, Hoogerwaard EM, Borm GF, Overeem S, Bloem BR; IMPACT study group. Integrated multidisciplinary care in Parkinson's disease: a non-randomised, controlled trial (IMPACT). Lancet Neurol. 2013;12(10):947-56. doi: 10.1016/S14744422(13)70196-0

[22] Willis AW, Schootman M, Tran R, Kung N, Evanoff BA, Perlmutter JS, Racette BA. Neurologist-associated reduction in PD-related hospitalizations and health care expenditures. Neurology. 2012;79(17):1774-80. doi: 10.1212/WNL.0b013e3182703f92

[23] Bourke D, Finucane G, Dysart J, Roxburgh R. The appointment of a Huntington's disease nurse specialist has reduced admission rate and improved admission quality. J Huntingtons Dis. 2012;1(1):27-30. doi: 10.3233/JHD-2012-120003 